\title{
Human listeriosis in England, 2001-2007: association with neighbourhood deprivation
}

I A Gillespie (iain.gillespie@hpa.org.uk)1, P Mook ${ }^{1}$, C L Little ${ }^{1}$, K A Grant ${ }^{1}$, J McLauchlin ${ }^{2}$

1. Health Protection Agency, Centre for Infections, London, United Kingdom

2. Health Protection Agency, Regional Microbiology Network, London, United Kingdom

Gillespie IA, Mook P, Little CL, Grant KA, McLauchlin J. Human listeriosis in England, 2001-2007: association with neighbourhood deprivation. Euro Surveill. 2010;15(27):pii=19609. Available online: http://www.eurosurveillance.org/ViewArticle.aspx?Articleld=19609

Listeriosis is a rare but severe food-borne disease that predominantly affects pregnant women, the unborn, newborns, the elderly and immunocompromised people. Despite the high mortality rate of the disease, its socio-economic determinants have not been studied in detail, meaning that health inequalities that might exist in relation to this disease are not apparent. Laboratory surveillance data on listeriosis cases reported in England between 2001 and 2007 were linked to indices of deprivation and denominator data using patients' postcodes. Incidence relative to increasing quintiles of deprivation was calculated by fitting generalised linear models while controlling for population size. Patient food purchasing and consumption data were scrutinised and compared with commercial food purchasing denominator data to further quantify the observed differences in disease incidence. For all patient groups, listeriosis incidence was highest in the most deprived areas of England when compared with the most affluent, and cases were more likely to purchase foods from convenience stores or from local services (bakers, butchers, fishmongers and greengrocers) than the general population were. Patients' risk profile also changed with increasing neighbourhood deprivation. With increased life expectancy and rising food prices, food poverty could become an increasingly important driver for foodborne disease in the future. While United Kingdom Government policy should continue to focus on small food businesses to ensure sufficient levels of food hygiene expertise, tailored and targeted food safety advice on the avoidance of listeriosis is required for all vulnerable groups. Failure to do so may enhance health inequality across socio-economic groups.

\section{Introduction}

Listeriosis is a rare but severe food-borne disease caused by the opportunistic bacterium Listeria monocytogenes. Pregnant women, the unborn, newborns, the elderly and immunocompromised people are most commonly affected, with high associated mortality reported. Symptoms range from mild influenza-like or gastrointestinal illness to miscarriage, stillbirth, septicaemia, meningitis or encephalitis. Throughout the 1990s approximately 110 cases were reported annually in England and Wales, but from 2001 to 2008 an average of 188 annual cases were reported. The reasons for this increase - which has occurred almost exclusively in patients aged 60 years or older presenting with bacteraemia - are largely unknown [1]. Similar increases have been reported elsewhere in Europe [2,3].

The socio-economic determinants of human listeriosis have not been studied in detail before, despite numerous population-based studies of the disease [4-12]. Some studies have described the socio-economic aspects of suspected (i.e. undiagnosed) [13-16] and confirmed [17-24] gastrointestinal infections, but health inequalities that might exist in relation to listeriosis have not been investigated. A longitudinal study of human listeriosis in Bristol in England between 1983 and 1992 found that social classes I and II (higher social classes) were over-represented among cases when compared with the general population $(45 \%$ versus $28 \%$ ) [25]. Only 29 cases were included in this study, however, and social class data were only available for 20 of these, hence the estimates were subject to sampling variability (note the $95 \%$ confidence intervals $(\mathrm{Cl})$ around the above proportions: $45 \%(95 \% \mathrm{Cl}$ : 23.2 to 66.8 ) and $28 \%$ (95\% Cl: 27.8 to 28.2 )). In order to systematically study the role of neighbourhood deprivation in human listeriosis for a larger population and over a longer time period, English national laboratory surveillance data for the period 2001 to 2007 were interrogated.

National surveillance for listeriosis in England and Wales is coordinated by the Health Protection Agency Centre for Infections. Following the voluntary referral of $L$. monocytogenes isolates for confirmation and subtyping [26-28] and/or local electronic reporting of confirmed cases, standardised clinical and epidemiological data are sought from hospital microbiologists and public health practitioners respectively [29]. The data are supplied through completion of questionnaires, which have been in use since 1990 (for hospital microbiologists) and 2005 (for public health practitioners) [29]. Epidemiological data are not routinely sought when the patient is deceased but are sometimes received. All data are stored in a bespoke database. 


\section{Methods}

\section{Case definitions}

For the purposes of surveillance, a case of listeriosis is defined as a person with a clinically compatible illness from whom L. monocytogenes was isolated from a normally sterile site. Cases are classified further as pregnancy-associated (all maternal-fetal patients and neonatal patients, with a mother-baby pair considered a single case) or non pregnancy-associated (when the illness occurs in patients more than one month of age). Patients' ethnicity - classed as 'ethnic' if deemed to be from an ethnic minority, or 'non-ethnic' if not - was assigned to all cases using patients' names (surname and first name as available). It is important to note that this classification, undertaken by two of the authors (IAG and PM), is distinct from patients' own classification of their ethnicity, based on the 2001 United Kingdom (UK) census [30] and captured on the standardised epidemiological questionnaire. Due to restrictions in the availability of denominator data, our study was limited to cases reported from laboratories in England.

\section{Analysis 1. Listeriosis incidence calculations}

On the basis of their home postcode, cases were assigned to the Office for National Statistics' lower super output areas (LSOAs) - the smallest geographical area for which aggregated census data are routinely released, comprising 32,482 areas in England and containing on average 1,500 residents per area. We then calculated the number of all non pregnancy-associated cases, non pregnancy-associated cases aged 60 years or older and pregnancy-associated cases resident in each LSOA in each year from 2001 to 2007. Respective population data (the number of all people, all people aged 60 years or older and all live births) for each LSOA in each year were obtained from the Office for National Statistics (the number of conceptions by LSOA were unavailable). These data were combined with 2007 multiple and individual indices of deprivation [31], giving 227,374 observations.

Subsequent data manipulation and analyses were undertaken using Stata version 10 [32].

The 2007 indices of deprivation consist of seven dimensions of deprivation (income; employment; health deprivation and disability; education, skills and training; barriers to housing and services; crime and disorder; living environment) which are weighted and combined [33] to create the overall index of multiple deprivation. A rank is also provided for each dimension and the overall index, where one is the most deprived LSOA and 32,482 the least. Variables were created to represent quintiles of each dimension rank and the index of multiple deprivation, but coded to compare the least deprived LSOAs with the most. As there were instances where there were no live births in certain LSOAs in some years, data for pregnancy-associated cases were grouped further (sums of cases and population counts;

\section{TABLE 1}

Characteristics of listeriosis cases included or excluded in the study on the basis of postcode availability, England, 2001-2007 (N=1,242)

\begin{tabular}{|c|c|c|}
\hline \multirow{3}{*}{ Factor } & \multicolumn{2}{|c|}{ Postcode available } \\
\hline & \multirow{2}{*}{$\begin{array}{c}\text { Yes } \\
(n=1,179) \\
\text { Number }(\%)^{\mathrm{a}}\end{array}$} & \multirow{3}{*}{$\begin{array}{c}\text { No } \\
(\mathrm{n}=63)\end{array}$} \\
\hline & & \\
\hline \multicolumn{2}{|l|}{ Study year } & \\
\hline 2001 & $112(86)^{b}$ & $18(14)^{\mathrm{b}}$ \\
\hline 2002 & $106(81)^{\mathrm{b}}$ & $25(19)^{b}$ \\
\hline 2003 & $202 \quad(91)^{\mathrm{b}}$ & $20(9)^{\mathrm{b}}$ \\
\hline 2004 & $193(100)^{b}$ & $0 \quad(0)$ \\
\hline 2005 & $179(100)^{b}$ & $0 \quad(0)$ \\
\hline 2006 & $176(100)^{b}$ & $0 \quad(0)$ \\
\hline 2007 & $211(100)^{b}$ & $0 \quad(0)$ \\
\hline \multicolumn{3}{|l|}{ Case type } \\
\hline Non pregnancy-associated & $1033 \quad(88)$ & $51(81)$ \\
\hline Pregnancy-associated & $146 \quad(12)$ & $12(19)$ \\
\hline \multicolumn{3}{|l|}{ Age group } \\
\hline$<60$ years & $385 \quad(33)$ & $31(49)$ \\
\hline$\geq 60$ years & $783 \quad(66)$ & $27(43)$ \\
\hline Unknown & (1) & $5 \quad(8)$ \\
\hline \multicolumn{3}{|l|}{ Ethnicity (based on name) } \\
\hline Ethnic & 140 & $12(19)$ \\
\hline Non-ethnic & $1033 \quad(88)$ & $44(70)$ \\
\hline Undetermined & (1) & $7 \quad(11)$ \\
\hline
\end{tabular}

${ }^{a}$ Column percentage, unless stated otherwise.

${ }^{b}$ Row percentage. 


\section{TABLE 2}

Incidence of listeriosis in relation to various markers for increasing deprivation, England, 2001-2007 (N=1,242)

\begin{tabular}{|c|c|c|c|c|}
\hline \multirow{3}{*}{$\begin{array}{l}\text { Increasing } \\
\text { deprivation } \\
\text { quintile }\end{array}$} & \multicolumn{4}{|c|}{ Incidence relative to the least-deprived quintile ( $95 \%$ confidence interval) } \\
\hline & \multirow{2}{*}{ All cases } & \multicolumn{2}{|c|}{ Non-pregnancy-associated cases } & \multirow{2}{*}{ Pregnancy-associated cases ${ }^{a}$} \\
\hline & & All & $\geq 60$ years & \\
\hline \multicolumn{5}{|c|}{ Indices of multiple deprivation } \\
\hline 1 (least) & 1 & 1 & 1 & 1 \\
\hline 2 & $1.02(0.84-1.23)$ & $0.98(0.80-1.20)$ & $0.94(0.74-1.18)$ & $1.16(0.54-2.51)$ \\
\hline 3 & $0.93(0.77-1.13)$ & $0.98(0.81-1.20)$ & $0.96(0.76-1.21)$ & $0.94(0.42-2.10)$ \\
\hline 4 & $1.16(0.97-1.40)$ & $1.09(0.90-1.33)$ & $1.21(0.96-1.52)$ & $2.34(1.24-4.40)$ \\
\hline 5 (most) & $1.38(1.16-1.65)$ & $1.27(1.05-1.53)$ & $1.36(1.09-1.71)$ & $2.20(1.18-4.08)$ \\
\hline \multicolumn{5}{|l|}{ Income } \\
\hline 1 (least) & 1 & 1 & 1 & 1 \\
\hline 2 & $0.98(0.82-1.19)$ & $0.99(0.82-1.21)$ & $0.97(0.77-1.22)$ & $1.26(0.58-2.74)$ \\
\hline 3 & $0.77(0.63-0.94)$ & $0.83(0.67-1.02)$ & $0.83(0.66-1.06)$ & $1.21(0.56-2.62)$ \\
\hline 4 & $1.18(0.98-1.41)$ & $1.16(0.96-1.40)$ & $1.24(1.00-1.55)$ & $2.38(1.24-4.60)$ \\
\hline 5 (most) & $1.25(1.05-1.49)$ & $1.17(0.97-1.42)$ & $1.31(1.04-1.64)$ & $2.10(1.10-4.00)$ \\
\hline \multicolumn{5}{|l|}{ Employment } \\
\hline 1 (least) & 1 & 1 & 1 & 1 \\
\hline 2 & $1.18(0.97-1.43)$ & $1.15(0.94-1.41)$ & $1.10(0.87-1.39)$ & $1.35(0.62-2.95)$ \\
\hline 3 & $1.15(0.95-1.40)$ & $1.17(0.95-1.43)$ & $1.07(0.84-1.36)$ & $1.32(0.63-2.76)$ \\
\hline 4 & $1.22(1.01-1.48)$ & $1.16(0.95-1.43)$ & $1.22(0.96-1.55)$ & $2.31(1.18-4.52)$ \\
\hline 5 (most) & $1.61(1.34-1.93)$ & $1.50(1.24-1.82)$ & $1.43(1.14-1.80)$ & $2.68(1.41-5.08)$ \\
\hline \multicolumn{5}{|c|}{ Health deprivation and disability } \\
\hline 1 (least) & 1 & 1 & 1 & 1 \\
\hline 2 & $0.97(0.80-1.18)$ & $0.92(0.75-1.13)$ & $0.98(0.77-1.24)$ & $1.04(0.47-2.33)$ \\
\hline 3 & $1.13(0.93-1.36)$ & $1.08(0.89-1.32)$ & $1.12(0.89-1.42)$ & $1.19(0.55-2.59)$ \\
\hline 4 & $1.17(0.97-1.41)$ & $1.09(0.90-1.33)$ & $1.24(0.98-1.56)$ & $2.12(1.09-4.12)$ \\
\hline 5 (most) & $1.54(1.29-1.84)$ & $1.37(1.14-1.66)$ & $1.48(1.18-1.85)$ & $2.58(1.36-4.89)$ \\
\hline \multicolumn{5}{|c|}{ Education, skills and training } \\
\hline 1 (least) & 1 & 1 & 1 & 1 \\
\hline 2 & $0.88(0.73-1.06)$ & $0.87(0.72-1.06)$ & $1.02(0.82-1.28)$ & $2.10(1.10-4.03)$ \\
\hline 3 & $0.84(0.69-1.01)$ & $0.78(0.64-0.95)$ & $0.89(0.70-1.12)$ & $1.78(0.91-3.46)$ \\
\hline 4 & $1.01(0.84-1.20)$ & $0.95(0.78-1.14)$ & $1.11(0.89-1.39)$ & $2.29(1.23-4.27)$ \\
\hline 5 (most) & $1.08(0.90-1.28)$ & $1.02(0.85-1.23)$ & $1.20(0.96-1.50)$ & $1.73(0.92-3.26)$ \\
\hline \multicolumn{5}{|c|}{ Barriers to housing and services } \\
\hline 1 (least) & 1 & 1 & 1 & 1 \\
\hline 2 & $0.88(0.74-1.06)$ & $0.96(0.79-1.16)$ & $0.95(0.76-1.19)$ & $0.60(0.35-1.02)$ \\
\hline 3 & $0.87(0.72-1.04)$ & $0.95(0.78-1.15)$ & $1.03(0.83-1.29)$ & $0.86(0.52-1.40)$ \\
\hline 4 & $0.87(0.73-1.04)$ & $0.94(0.77-1.14)$ & $0.92(0.73-1.15)$ & $0.63(0.36-1.11)$ \\
\hline 5 (most) & $0.92(0.77-1.09)$ & $0.93(0.77-1.13)$ & $1.01(0.80-1.26)$ & $0.84(0.54-1.31)$ \\
\hline \multicolumn{5}{|c|}{ Crime and disorder } \\
\hline 1 (least) & 1 & 1 & 1 & 1 \\
\hline 2 & $0.92(0.76-1.12)$ & $0.90(0.74-1.10)$ & $1.01(0.80-1.28)$ & $0.95(0.36-2.50)$ \\
\hline 3 & $1.19(0.99-1.43)$ & $1.07(0.88-1.30)$ & $1.23(0.98-1.54)$ & $1.76(0.75-4.17)$ \\
\hline 4 & $1.20(1.001-1.44)$ & $1.17(0.96-1.41)$ & $1.32(1.05-1.65)$ & $2.21(0.99-4.93)$ \\
\hline 5 (most) & $1.20(1.003-1.44)$ & $1.09(0.90-1.33)$ & $1.43(1.14-1.79)$ & $2.53(1.16-5.51)$ \\
\hline \multicolumn{5}{|c|}{ Living environment } \\
\hline 1 (least) & 1 & 1 & 1 & 1 \\
\hline 2 & $1.02(0.84-1.24)$ & $1.00(0.82-1.22)$ & $0.96(0.76-1.21)$ & $1.73(0.83-3.64)$ \\
\hline 3 & $1.11(0.92-1.34)$ & $1.09(0.90-1.33)$ & $1.05(0.84-1.32)$ & $1.22(0.56-2.66)$ \\
\hline 4 & $1.28(1.07-1.54)$ & $1.24(1.02-1.50)$ & $1.32(1.06-1.65)$ & $1.90(0.95-3.82)$ \\
\hline 5 (most) & $1.21(1.01-1.45)$ & $1.04(0.86-1.27)$ & $1.12(0.88-1.42)$ & $2.71(1.44-5.11)$ \\
\hline
\end{tabular}

${ }^{a}$ Calculated at the local authority rather than the lower super output area (LSOA) level. 
averages of deprivation measures) and quintiles recalculated to allow analysis at the larger local authority level.

Estimates of the incidence of listeriosis relative to increasing deprivation were obtained by fitting generalised linear models with a count of cases per LSOA or local authority per year as the outcome variable. Incidence in each quintile relative to the lowest quintile of deprivation (least deprived) was calculated. Four sets of analyses were undertaken: all cases, all non pregnancy-associated cases, non pregnancy-associated cases aged 60 years or older and pregnancy-associated cases. In each, a log-link function was included to control for the underlying population (all people, people aged 60 years or older and all live births as appropriate) in each LSOA or local authority in each year. Chi-square tests and chi-square tests for trend, performed in Epi Info version 6.04d [34], were used to assess simple comparisons of proportions or trend in proportions respectively.
Analysis 2. Food purchasing comparison

To inform further on the findings of the incidence calculations, patients' food purchasing patterns were examined in relation to commercial denominator data. The standardised epidemiological questionnaire includes questions on various retail premises where cases had recently purchased food. These data, available from 2005 to 2007, were interrogated to obtain the number of cases reporting food shopping in different types of retailer. Commercial denominator data for the same time period and population were obtained from the Worldpanel Purchase database from the market research company Taylor Nelson Sofres (TNS, London). This database is the largest continuous consumer panel in Great Britain, capturing purchasing behaviour for 48,000 individuals in 25,000 households, and is used extensively by major retailers and manufacturers in the UK to understand consumer behaviour. Participants, chosen to be representative of Great Britain as a whole in terms of age, social class and region, record retail purchases by various means (e.g. bar code scanners, online surveys, till receipt scanning, etc.) and report to TNS fortnightly. Crude data were obtained from the database for the total number of individuals and the

\section{TABLE 3}

Characteristics of listeriosis cases, according to receipt of epidemiological questionnaires, England, 2005-2007 (n=566)

\begin{tabular}{|c|c|c|}
\hline \multirow[b]{2}{*}{ Parameter } & \multicolumn{2}{|c|}{ Epidemiological questionnaire received } \\
\hline & $\begin{array}{c}\text { Yes } \\
(n=231) \\
\text { Number }(\%)^{a}\end{array}$ & $\begin{array}{c}\text { No } \\
(\mathrm{n}=335) \\
\text { Number }(\%)^{\mathrm{a}}\end{array}$ \\
\hline \multicolumn{3}{|l|}{ Patient type } \\
\hline Pregnancy-associated & $39 \quad(17)$ & $38 \quad(11)$ \\
\hline Non pregnancy-associated & $192 \quad(83)$ & $297 \quad(89)$ \\
\hline \multicolumn{3}{|l|}{ Year } \\
\hline 2005 & $37 \quad(21)^{b}$ & $142(79)^{b}$ \\
\hline 2006 & $50 \quad(28)^{b}$ & $126(72)^{b}$ \\
\hline 2007 & $144(68)^{b}$ & $67(32)^{b}$ \\
\hline \multicolumn{3}{|l|}{ Gender } \\
\hline Male & $121 \quad(52)$ & $165 \quad(49)$ \\
\hline Female & $110 \quad(48)$ & $168 \quad(50)$ \\
\hline Unknown & $0 \quad(0)$ & $2 \quad(1)$ \\
\hline \multicolumn{3}{|l|}{ Age } \\
\hline Median & 65 years & 68 years \\
\hline Interquartile range & $42-76$ years & $55-79$ years \\
\hline \multicolumn{3}{|c|}{ Quintile of increasing deprivation ${ }^{c}$} \\
\hline 1 (least) & $44(19.0)$ & $59 \quad(18)$ \\
\hline 2 & $35 \quad(15.2)$ & $79 \quad(24)$ \\
\hline 3 & $41 \quad(17.7)$ & $54 \quad(16)$ \\
\hline 4 & $48(20.8)$ & $72 \quad(21)$ \\
\hline 5 (most) & $62(26.8)$ & $67 \quad(20)$ \\
\hline Unknown & $1 \quad(0.4)$ & $4 \quad(1)$ \\
\hline \multicolumn{3}{|l|}{ Mortality } \\
\hline Died & $62 \quad(27)$ & $111 \quad$ (33) \\
\hline Did not die & $167 \quad(72)$ & $128 \quad(38)$ \\
\hline Unknown & $2 \quad(1)$ & $96 \quad(29)$ \\
\hline
\end{tabular}

a Column percentage, unless stated otherwise.

${ }^{b}$ Row percentage.

c Indices of multiple deprivation. 
total number of individuals aged 60 years or older, and the food purchasing habits of both groups from various supermarkets, discount supermarkets, convenience stores (typically small retail stores selling limited produce over extended periods) and local services (corner shops, local butchers, bakers, greengrocers and fishmongers). Reported places for food shopping among cases and the general population were compared in Microsoft Excel 2007. Odds ratios (OR) and 95\% Cls were calculated.

Analysis 3. Food purchasing, storage

and consumption in relation to quintiles of multiple deprivation

Finally, the quintiles of the index of multiple deprivation calculated in analysis 1 above were combined with the standardised food purchasing, storage and consumption data from analysis 2 and data were stratified by quintiles of increasing neighbourhood deprivation. Changes in the upwards or downwards trend in relation to increasing deprivation were assessed using the chisquare test for trend.

\section{Results}

\section{Study population}

Between 2001 and 2007, 1,242 cases of human listeriosis were reported; of these, $1,084(87 \%)$ were non pregnancy-associated and 158 (13\%) were pregnancyassociated. Where patient age was available for non pregnancy-associated cases $(n=1,072), 810(76 \%)$ of cases were aged 60 years or older. Patients' home postcodes were available for $1,179(95 \%)$ cases and all matched to an LSOA (Table 1). Postcode availability increased significantly over the surveillance period (chi-square test for trend P<0.001), but postcodes were more likely to be unavailable for patients aged under 60 years (chi-square test $p=0.001$ ) or for those defined as ethnic on the basis of their names (chi-square test $\mathrm{p}=0.04)$ (Table 1).

\section{Incidence by quintiles of deprivation}

The incidence of listeriosis increased with increasing relative neighbourhood deprivation (Table 2), with $38 \%$ ( $95 \% \mathrm{Cl}: 16$ to 65$)$ higher incidence in the most deprived quintile compared with the least. Incidence was positively correlated with all of the dimensions of deprivation (reflecting their intracorrelation and their

TABLE 4

Food purchase patterns for listeriosis cases $(n=171)$ compared with those of the general population $(n=60,415)$, England, 2005-2007

\begin{tabular}{|c|c|c|c|c|c|c|}
\hline \multirow[b]{2}{*}{ Premises } & \multicolumn{6}{|c|}{ Food shopping by premises } \\
\hline & $\begin{array}{c}\text { All cases } \\
\text { n (\%) }\end{array}$ & $\begin{array}{l}\text { Population }^{\mathrm{a}} \\
\text { n (\%) }\end{array}$ & OR $(95 \% \mathrm{Cl})$ & $\begin{array}{l}\text { Cases aged } \\
\geq 60 \text { years } \\
n(\%)\end{array}$ & $\begin{array}{l}\text { Population aged } \\
\begin{array}{c}\geq 0 \text { years }^{\mathrm{a}} \\
\text { n (\%) }\end{array}\end{array}$ & OR $(95 \% \mathrm{Cl})$ \\
\hline \multicolumn{7}{|l|}{ Supermarkets } \\
\hline Chain B & $85(49.7)$ & $47,811 \quad(79.1)$ & $0.26(0.19-0.35)$ & $44(42.3)$ & $11,383(75.2)$ & $0.24(0.16-0.36)$ \\
\hline Chain G & $63(36.8)$ & $37,238(61.6)$ & $0.36(0.27-0.50]$ & $35(33.7)$ & $8,063(53.2)$ & $0.45(0.30-0.67)$ \\
\hline Chain J & $63(36.8)$ & $35,475(58.7)$ & $0.41(0.30-0.56)$ & $34(32.7)$ & $9,315(61.5)$ & $0.30(0.20-0.46)$ \\
\hline Chain A & $55(32.2)$ & $30,596(50.6)$ & $0.46(0.34-0.64)$ & $35(33.7)$ & $8,000(52.8)$ & $0.45(0.30-0.68)$ \\
\hline Chain D & $48(28.1)$ & $24,225(40.1)$ & $0.58(0.42-0.81)$ & $32(30.8)$ & $8,050(53.2)$ & $0.39(0.26-0.59)$ \\
\hline Chain $\mathrm{K}$ & $27(15.8)$ & $19,935(33.0)$ & $0.38(0.25-0.57)$ & $13(12.5)$ & $5,259(34.7)$ & $0.27(0.15-0.48)$ \\
\hline Chain U & $24(14.0)$ & $18,993(31.4)$ & $0.36(0.23-0.55)$ & $15(14.4)$ & $5,579(36.8)$ & $0.29(0.17-0.50)$ \\
\hline Chain P & $15(8.8)$ & $10,025(16.6)$ & $0.48(0.28-0.82)$ & $7(6.7)$ & $3,372(22.3)$ & $0.25(0.12-0.54)$ \\
\hline \multicolumn{7}{|c|}{ Discount supermarkets } \\
\hline Chain X & $15(8.8)$ & $15,568(25.8)$ & $0.28(0.16-0.47)$ & $7(6.7)$ & $5,032(33.2)$ & $0.15(0.07-0.31)$ \\
\hline Chain Q & $16(9.4)$ & $14,500(24.0)$ & $0.33(0.20-0.55)$ & $8(7.7)$ & $4,279(28.3)$ & $0.21(0.10-0.44)$ \\
\hline Chain C & $7(4.1)$ & $7,605(12.6)$ & $0.30(0.14-0.63)$ & $4(3.8)$ & $2,004(13.2)$ & $0.26(0.10-0.71)$ \\
\hline Chain E & $9(5.3)$ & $5,594 \quad(9.3)$ & $0.54(0.28-1.07)$ & $7(6.7)$ & $1,715(11.3)$ & $0.57(0.26-1.22)$ \\
\hline \multicolumn{7}{|c|}{ Convenience stores } \\
\hline Chain $\mathrm{H}$ & $4(2.3)$ & $3,534 \quad(5.8)$ & $0.39(0.14-1.04)$ & $1(1.0)$ & $1,184(7.8)$ & $0.11(0.02-0.82)$ \\
\hline Chain L & $10 \quad(5.8)$ & $3,846(6.4)$ & $0.91(0.48-1.73)$ & $5(4.8)$ & $1,013(6.7)$ & $0.70(0.29-1.73)$ \\
\hline Chain M & $26(15.2)$ & $1,952 \quad(3.2)$ & $5.37(3.53-8.17)$ & $17(16.3)$ & $668(4.4)$ & $4.23(2.50-7.16)$ \\
\hline \multicolumn{7}{|l|}{ Local services } \\
\hline Corner shops & $44(25.7)$ & 13,864 (22.9) & $1.16(0.83-1.64)$ & $15(14.4)$ & $4,241(28.0)$ & $0.43(0.25-0.75)$ \\
\hline Butchers & $35(20.5)$ & $8,300 \quad(13.7)$ & $1.62(1.11-2.34)$ & $17(16.3)$ & $3,510(23.2)$ & $0.65(0.38-1.09)$ \\
\hline Green grocers & $35(20.5)$ & $7,155 \quad(11.8)$ & $1.92(1.32-2.78)$ & $16(15.4)$ & $3,148(20.8)$ & $0.69(0.41-1.18)$ \\
\hline Bakers & $40(23.4)$ & 4,973 (8.2) & $3.40(2.39-4.86)$ & $23(22.1)$ & $2,140(14.1)$ & $1.73(1.08-2.75)$ \\
\hline Fishmongers & $21(12.3)$ & $1,631 \quad(2.7)$ & $5.05(3.19-7.99)$ & $11(10.6)$ & $938 \quad(6.2)$ & $1.79(0.96-3.36)$ \\
\hline
\end{tabular}

$\mathrm{Cl}$ : confidence interval; OR: odds ratio.

a Source: commercial market research data. 
contribution to the overall index of multiple deprivation) except 'education, skills and training' and 'barriers to housing and services' domains. Incidence in non pregnancy-associated cases generally followed that for all cases and was more marked for those cases aged 60 years or older. The incidence of pregnancyassociated listeriosis showed a more marked association with increasing neighbourhood deprivation, with the strongest associations observed with the 'income', 'employment' and 'health deprivation and disability' domains.

\section{Standardised patient exposure}

data (2005-2007)

Between 1 January 2005 and 31 December 2007, 231 epidemiological questionnaires were received for the 566 reported cases in England (response rate 41\%), with the response rate increasing significantly over the surveillance period (chi-square test for trend pro.001) (Table 3). Surveillance questionnaire receipt was independent of case type (chi-square test $p=0.06$ ), age (chi-square test $p=0.09$ ), sex (chi-square test $p=0.5$ ) and level of deprivation (chi-square test $p=0.09$ ), but not mortality (chi-square test pro.001) (Table 3). A total of 20 non-standard and 40 partially completed questionnaires were excluded, leaving 171 for analysis.

Of the 32 cases classed as ethnic on the basis of their name, 29 described their ethnicity as something other than 'white British', compared with 16 of 138 cases classed as non-ethnic (positive predictive value: $90.6 \%$ (95\% Cl: 86.2 to 95.0); negative predictive value: $88.4 \%$ (95\% Cl: 83.6 to 93.2 ). One case classed as non-ethnic on the basis of their name did not describe their own ethnicity.

\section{Food purchasing patterns in relation to}

the general population (2005-2007)

The use of supermarkets and discount supermarkets was underrepresented among cases of listeriosis when compared with the general population, while the use of national convenience store chain $M$, and most local services, was overrepresented (Table 4). This relationship was observed to a lesser extent for cases aged 60 years or older, but could not be determined for pregnancy-associated cases due to a lack of denominator data. Cases who reported food shopping at national convenience store chain $M$ were equally distributed across all quintiles of deprivation (chi-square for trend test $p=0.38$ ), were infected with nine different $L$. monocytogenes subtypes and food shopping at this store was overrepresented in each study year: OR: 6.00 (95\% Cl: 1.75 to 20.56) in 2005; OR: 6.16 (95\% Cl: 2.72 to 13.91 ) in 2006; OR: 4.67 (95\% Cl: 2.7 to 7.97 ) in 2007 , suggesting that this association did not represent a single outbreak due to a single or restricted range of L. monocytogenes strains.
Food purchasing, storage and consumption in relation to quintiles of multiple deprivation (2005-2007; data not shown) As quintiles of neighbourhood deprivation increased, cases $(n=171)$ were more likely to describe their ethnicity as something other than white British (chi-square test for trend $p=0.01$ ) and were more likely to report:

- avoiding soft blue cheese (chi-square test for trend $p=0.04$ )

- avoiding pâté (chi-square test for trend $p=0.01$ ).

They were more likely to report eating:

- liver sausage (chi-square test for trend $p=0.04$ )

- cold roast turkey (chi-square test for trend $p=0.045$ )

- pre-packed cold turkey (chi-square test for trend $\mathrm{p}=0.048$ ).

They were less likely to report eating:

- food from hotels (chi-square test for trend $p=0.01$ )

- food from restaurants serving British cuisine (chisquare test for trend $p=0.04$ )

- duck liver pâté (chi-square test for trend $p=0.049$ )

- oysters (chi-square test for trend $p=0.03$ )

- watercress (chi-square test for trend $p=0.03$ ).

They were more likely to report recent food shopping in:

- national supermarket chain $\mathrm{G}$ (chi-square test for trend $p=0.001$ )

- national supermarket chain K (chi-square test for trend $p=0.006$ )

- national discount supermarket chain X (chi-square test for trend $p=0.004$ )

- local bakers (chi-square test for trend $p=0.02$ )

- fishmongers (chi-square test for trend $p=0.03$ )

- greengrocers (chi-square test for trend p<0.001).

They were no more likely to have acute or long-standing medical conditions (chi-square test for trend $p=0.22$ ).

\section{Discussion and conclusion}

Laboratory-based surveillance of human L. monocytogenes infection in England between 2001 and 2007 revealed that incidence was highest in the most deprived areas of the country. Additional analyses demonstrated that cases of listeriosis were more likely than the general population to purchase foods from convenience stores or from local services, and that among cases, food purchasing and consumption patterns changed with increasing deprivation. While cases of listeriosis form the numerator in each of the three analyses presented, the denominators are either different or are absent, and therefore the findings of each are not necessarily comparable.

Cases in this study comprise laboratory-confirmed cases reported to national surveillance. Reporting will be affected by disease severity, health-seeking behaviour and reporting artefacts, all of which will 
have a bearing on incidence estimates. Infection with L. monocytogenes results in a range of symptoms, and laboratory surveillance will undoubtedly underascertain milder forms of the disease. Disease severity relates largely to the degree of exposure and susceptibility of the host, and both might be driven by socioeconomic factors (income-related food consumption leading to a greater or lesser exposure; known associations between certain underlying conditions (e.g. cancer [35], general poor health [36,37], diabetes [38]) and socio-economic status). By using laboratory-confirmed cases we might therefore be biasing our estimates for certain socio-economic groups. Community-based studies would be prohibitively expensive for a disease as rare as listeriosis, however, and without undertaking such studies it is impossible to measure the extent or direction of this bias in our study.

Healthcare usage also differs by socio-economic status for patients in England with infectious intestinal disease. Tam et al. demonstrated that individuals in lower socio-economic groups (as defined by age at leaving full-time education and housing) were more likely to present with infectious intestinal disease to a general practice than community controls were [39]. This might explain some of the observed difference in incidence by socio-economic status in our study. Tam's study included all causes of infectious intestinal disease, however, and it is not possible to determine how this differential presentation might relate to listeriosis, which differs markedly from most gastrointestinal infections in terms of severity, symptoms and population at risk.

National surveillance of listeriosis in England and Wales is passive, hence our estimates might be affected if clinicians' reporting practices differ depending on their patients' socio-economic status. In their study of listeriosis in Bristol, Jones et al. noted that the incidence in 1988 (1.2 cases per 100,000 population) was higher than the national average ( 0.58 cases per 100,000 population), suggesting that not all cases were reported to national surveillance and thus creating the opportunity for this form of selection bias [25]. The confidence intervals surrounding the above estimates overlap ( 0.58 to 2.24 per 100,000 population for Bristol; 0.5799 to 0.5801 per 100,000 population for England and Wales), however, suggesting no actual difference between incidence at the local and national level, and that the majority of cases confirmed at the local level are reported nationally.

We applied 2007 indices of deprivation to surveillance data from 2001 to 2007 , meaning that areas that hypothetically experienced extreme social change during this time might not be adequately represented by these indices for part of the surveillance period. Such changes will be exceptional over such a short period, so most of the data will be unaffected by this generalisation, and any effect will be minimised further by arranging the data in quintiles.
By assigning cases to socio-economic groups on the basis of their home postcode, the effect of socio-economic status at the individual level is masked and individuals take on the socio-economic characteristics of their local environment [13]. While the merits of assigning social class to individuals by postcode is debatable $[40,41]$ and the potential for ecological fallacy is increased, this method is advantageous in that it does not rely on high response rates to questionnaires (a particular problem for a severe disease such as listeriosis) or to potentially sensitive questions required for establishing socio-economic status (e.g. on income). Furthermore, the opportunity for misclassification through the direct derivation of socioeconomic status, based on occupation, for example [23], is minimised.

With these caveats in mind, the association between listeriosis and increasing deprivation reported in this study differs from other studies on the socio-economic determinants of gastrointestinal infections, where incidence was often positively associated with increased socio-economic status [17-24]. With pâté and soft mould-ripened cheese historically considered high-risk foods for listeriosis in the UK, our a priori hypothesis was that listeriosis would be a disease of affluence. The breakdowns in food safety that give rise to listeriosis differ from other food-borne pathogens, however, and these could impact on the demographics of the population at risk. While inadequate cooking of and/or cross-contamination from contaminated raw poultry meat increases the risk of campylobacteriosis, and inappropriate storage of uncooked or undercooked egg-based products over short time periods can lead to salmonellosis, the risk of listeriosis increases with the growth of L. monocytogenes to hazardous levels in refrigerated long shelf-life products [42]. It is possible that such conditions arise more frequently with increased deprivation where refrigeration may be inadequate or unavailable. Additionally, financial pressures may encourage individuals to store food for longer than the food product's safe shelf-life. Alternatively, as general poor health and certain chronic conditions such as cancers and diabetes are associated with lower socioeconomic status [35-38] it is therefore intuitive that Listeria incidence would be higher in poorer areas.

Home postcodes were available less often for ethnic patients, hence the observed association with increasing neighbourhood deprivation might be underestimated, as ethnic groups reside more frequently in more deprived areas of England [43]. As neighbourhood deprivation increased, cases were also more likely to report their ethnicity as something other than white British, suggesting that at least part of the overall association may be due to an increased risk of infection in ethnic minorities. Currently, specific UK Government food safety advice on minimising the risk of listeriosis is delivered passively (via a website [44]) and is targeted preferentially at pregnant women. Our study suggests that advice should be communicated proactively and effectively to all patient groups at risk 
of listeriosis, especially where language barriers exist, or where access to the Internet is limited [45]. Advice should be extended to include information on safe use and storage of foods in the home to avoid listeriosis (e.g. refrigerate once opened, consume within the shelf life of the product, etc.).

Several factors should be considered while interpreting our comparisons of cases' exposures in relation to increasing neighbourhood deprivation, and their food purchasing patterns with that observed in the general population. Firstly, routine surveillance of listeriosis is problematic due to the severity of the disease and the population at risk. For this reason, the response rate to our epidemiological questionnaire, while improving, is lower than for other active surveillance systems for gastrointestinal infections in England, e.g. $77 \%$ for verocytotoxin-producing Escherichia coli infection in England (Health Protection Agency, unpublished data) and is better for patients who survive their infection. It is possible that certain exposures will be underrepresented in our surveillance dataset if those exposures are linked to increased mortality, e.g. foods containing higher concentrations of $L$. monocytogenes or certain subtypes, or those consumed more often by the most vulnerable. To date, studies of $L$. monocytogenes mortality $[6,7,11]$ have focussed on host factors, making quantification of this potential bias impossible.
Secondly, the population at risk of listeriosis in England is not the same as the population of England, as listeriosis patients are often individuals predisposed to opportunistic infections due to suppression of their T-cell-mediated immunity [46], and the conditions that give rise to this immunological state might alter their behaviour, including food purchasing patterns. People tend to keep the same shopping habits though, and while they might avoid some foods due to certain underlying conditions (or their treatments), they are less likely to change their favoured supermarkets or shops. Finally, individuals participating in surveys of any kind will differ systematically from the general population by virtue of their willingness to participate, and this bias might be more profound for market research surveys where participation is often rewarded financially. Market research data are used extensively by many business sectors, however, and therefore there is an economic pressure on market research companies for their study participants to be as representative as possible, and the denominator data used matched closely to the British population with regard to age and social class. This could be detrimental to our food purchasing comparison, as the numerator (listeriosis cases in England, skewed towards increased deprivation) differs from the denominator (commercial data, representative in terms of social class), and this might explain some or all of the observed differences in food

\section{FIGURE}

Non-seasonally adjusted product price index for food products (excluding beverages), United Kingdom,

January 1991 - July 2009a

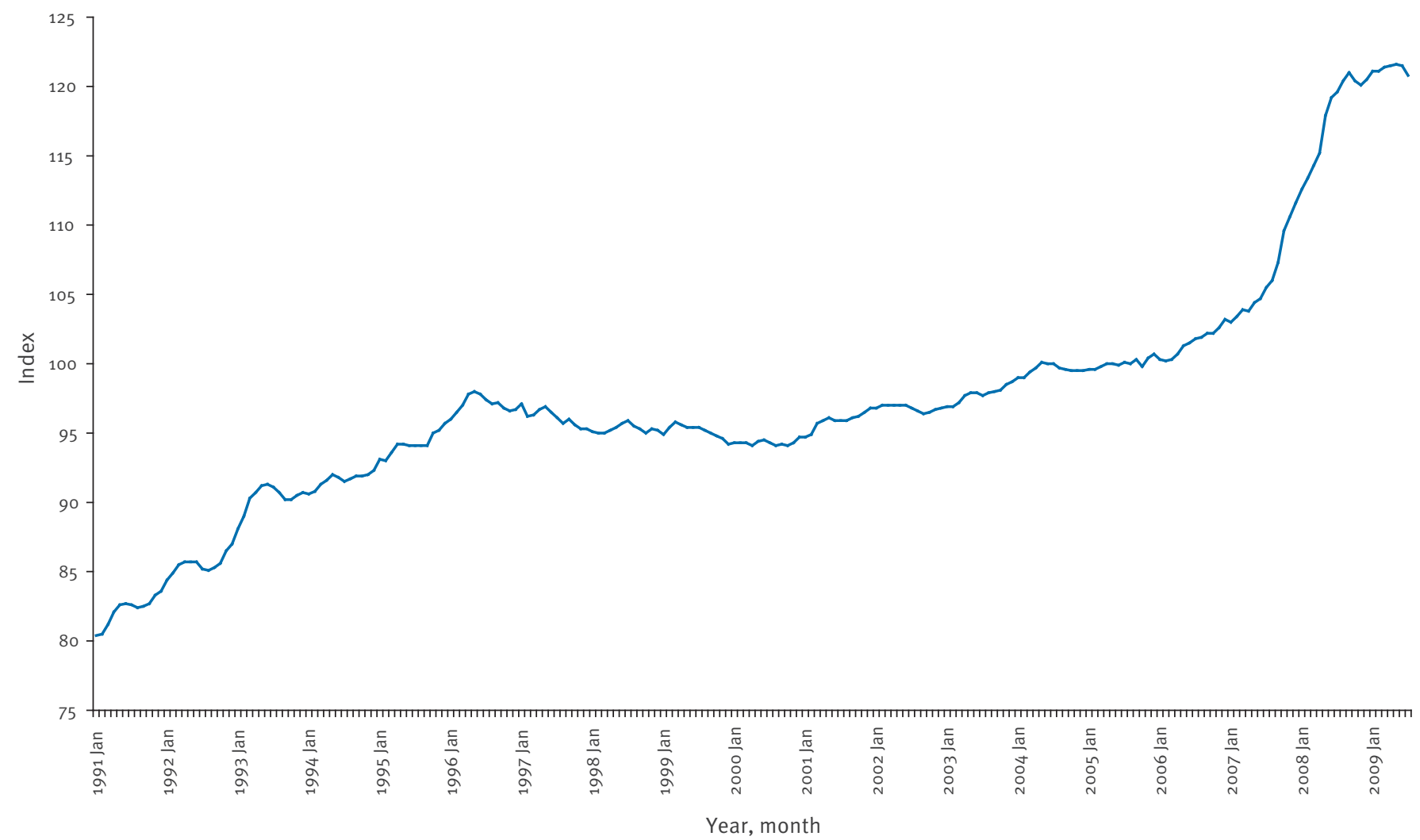

a Index set at 100 for 2005 .

Source: [52]. 
purchasing. Further work could address this shortcoming by examining the food purchasing patterns of cases in relation to deprivation-matched population groups, but the provision of such detailed denominator data was prohibitively expensive for this unfunded study. Discussions of the findings from this study are still warranted, however, as shopping for food at several of the 'over-indexed' types of premises (those reported more often by cases than by the general population) also increased among listeriosis cases as neighbourhood deprivation increased.

The apparent overuse of national convenience store chain $M$ by listeriosis cases may represent differential misclassification, as this chain is colloquially synonymous with small convenience stores in the UK, and therefore patients may report shopping there when they are in fact referring to any convenience store. Commercial data, on the other hand, will be ascribed correctly to the appropriate premises type, based on the comprehensive collection methods described previously. Similarly, the associations with local services might reflect the fact that, on average, a shopper would visit several shop types among their local services to purchase the variety of items that would be available in a single supermarket and therefore the numerator is inflated. Alternatively, residents in poorer areas may be limited to shopping locally due to poorer access to transportation. Convenience stores and local services generally represent the smaller end of the market in terms of business size, and this feature has been frequently linked to lower microbiological quality of foods in a number of surveys undertaken in England and Wales since 1994 [47]. Small businesses do not have access to the same level of food safety expertise [48] as larger retail companies do, and these food control deficiencies might increase the food safety risk for consumers. The 2006 'Safer food better business' initiative by the UK Government [49], designed to help small food businesses implement hazard-based control systems and to comply with food hygiene regulations, was therefore timely. Food safety management systems employed to satisfy legislation will only fully meet legal obligations, however, when they account for all relevant hazards and risks. Clearly $L$. monocytogenes and its associated food safety storage issues, which are different from those of other food-poisoning bacteria, must be considered carefully in food manufacturing and retail operations, particularly for foods sold to vulnerable individuals [50].

In conclusion, our study demonstrates that $L$. monocytogenes incidence was highest in the most deprived areas of England when compared with the most affluent, that cases were more likely to purchase foods from convenience stores or from local services than the general population were, and that patients' risk profile changed with increasing neighbourhood deprivation. Increasing 'healthy life expectancy' in the UK does not follow increasing life expectancy, meaning that in future, individuals may spend a greater part of their retirement in poor health [51]. With poor health in later life allied to increasing deprivation and recent rises in food prices (Figure [52]) predicted to continue, food poverty could become an increasingly important driver for listeriosis. While UK Government policy should continue to focus on small food businesses to ensure sufficient levels of food hygiene expertise, tailored and targeted food safety advice on the avoidance of listeriosis is required for all vulnerable groups within the community. Failure to do so will enhance health inequality across socio-economic groups.

\section{Acknowledgements}

Thanks are extended to the hospital microbiology, public health and environmental health professionals who contribute to this surveillance system. We are grateful to André Charlett and George Kafatos for statistical advice.

\section{References}

1. Gillespie IA, McLauchlin J, Grant KA, Little CL, Mithani V, Penman $C$, et al. Changing pattern of human listeriosis, England and Wales, 2001-2004. Emerg Infect Dis. 2006;12(9):1361-6.

2. Denny J, McLauchlin J. Human Listeria monocytogenes infections in Europe--an opportunity for improved European surveillance. Euro Surveill. 2008;27;13(13). pii: 8082. Available from: http://www.eurosurveillance.org/ViewArticle. aspx?Articleld $=8082$

3. Goulet V, Hedberg C, Le Monnier A, De Valk H. Increasing incidence of listeriosis in France and other European countries. Emerg Infect Dis. 2008;14(5):734-40.

4. Campbell DM. Human listeriosis in Scotland 1967-1988. J Infect. 1990;20(3):241-50.

5. Samuelsson S, Rothgardt NP, Carvajal A, Frederiksen W. Human listeriosis in Denmark 1981-1987 including an outbreak November 1985-March 1987. J Infect. 1990;20(3):251-9.

6. McLauchlin J. Human listeriosis in Britain, 1967-85, a summary of 722 cases. 2. Listeriosis in non-pregnant individuals, a changing pattern of infection and seasonal incidence. Epidemiol Infect. 1990;104(2)191-201.

7. Goulet V, Marchetti P. Listeriosis in 225 non-pregnant patients in 1992: clinical aspects and outcome in relation to predisposing conditions. Scand J Infect Dis. 1996;28(4):367-74.

8. Smerdon WJ, Jones R, McLauchlin J, Reacher M. Surveillance of listeriosis in England and Wales, 1995-1999. Commun Dis Public Health. 2001;4(3):188-93.

9. Hjaltested EK, Gudmundsdóttir S, Jónsdóttir K, Kristinsson KG, Steingrimsson 0, Kristjánsson M. Listeriosis in Iceland, 19782000: a description of cases and molecular epidemiology. Scand J Infect Dis. 2002;34(10):735-41.

10. Siegman-Igra Y, Levin R, Weinberger M, Golan Y, Schwartz D, Samra Z, et al. Listeria monocytogenes infection in Israel and review of cases worldwide. Emerg Infect Dis. 2002;8(3):305-10.

11. Gerner-Smidt P, Ethelberg S, Schiellerup P, Christensen J, Engberg J, Fussing V, et al. Invasive listeriosis in Denmark 1994-2003: a review of 299 cases with special emphasis on risk factors for mortality. Clin Microbiol Infect. 2005;11(8):618-24.

12. Doorduyn Y, de Jager CM, van der Zwaluw WK, Wannet WJ, van der EA, Spanjaard L, et al. Invasive Listeria monocytogenes infections in the Netherlands, 1995-2003. Eur J Clin Microbiol Infect Dis. 2006;25(7):433-42.

13. Bytzer P, Howell S, Leemon M, Young LI, Jones MP, Talley NJ. Low socioeconomic class is a risk factor for upper and lower gastrointestinal symptoms: a population based study in 15000 Australian adults. Gut. 2001;49(1):66-72.

14. Herikstad H, Yang S, Van Gilder TJ, Vugia D, Hadler J, Blake P, et al. A population-based estimate of the burden of diarrhoeal illness in the United States: FoodNet, 1996-7. Epidemiol Infect. 2002;129(1):9-17.

15. Majowicz SE, Doré K, Flint JA, Edge VL, Read S, Buffett MC, et al. Magnitude and distribution of acute, self-reported gastrointestinal illness in a Canadian community. Epidemiol Infect. 2004;132(4):607-17. 
16. Hall GV, Kirk MD, Ashbolt R, Stafford R, Lalor K. Frequency of infectious gastrointestinal illness in Australia, 2002: regional, seasonal and demographic variation. Epidemiol Infect. 2006;134(1):111-8.

17. Banatvala N, Cramp A, Jones IR, Feldman RA. Salmonellosis in North Thames (East), UK: associated risk factors. Epidemiol Infect. 1999;122(2):201-7.

18. Olowokure B, Hawker J, Weinberg J, Gill N, Sufi F. Deprivation and hospital admission for infectious intestinal diseases. Lancet. 1999;353(9155):807-8.

19. de Wit MA, Koopmans MP, Kortbeek LM, Wannet WJ, Vinjé J, van Leusden F, et al. Sensor, a population-based cohort study on gastroenteritis in the Netherlands: incidence and etiology. Am J Epidemiol. 2001;154(7):666-74.

20. Green CG, Krause DO, Wylie JL. Spatial analysis of campylobacter infection in the Canadian province of Manitoba. Int J Health Geogr. 2006;5:2.

21. Lake IR, Harrison FC, Chalmers RM, Bentham G, Nichols G, Hunter PR, et al. Case-control study of environmental and social factors influencing cryptosporidiosis. Eur J Epidemiol. 2007;22(11):805-11.

22. Younus M, Hartwick E, Siddiqi AA, Wilkins M, Davies HD, Rahbar M, et al. The role of neighborhood level socioeconomic characteristics in Salmonella infections in Michigan (19972007): assessment using geographic information system. Int J Health Geogr. 2007;6:56.

23. Gillespie IA, O’Brien SJ, Penman C, Tompkins D, Cowden J, Humphrey TJ. Demographic determinants for Campylobacter infection in England and Wales: implications for future epidemiological studies. Epidemiol Infect. 2008;136(12):1717-25.

24. Simonsen J, Frisch M, Ethelberg S. Socioeconomic risk factors for bacterial gastrointestinal infections. Epidemiology. 2008;19(2):282-90.

25. Jones EM, McCulloch SY, Reeves DS, MacGowan AP. A 10 year survey of the epidemiology and clinical aspects of listeriosis in a provincial English city. J Infect 1994;29(1):91-103.

26. Nogva HK, Rudi K, Naterstad K, Holck A, Lillehaug D. Application of 5'-nuclease PCR for quantitative detection of Listeria monocytogenes in pure cultures, water, skim milk, and unpasteurized whole milk. Appl Environ Microbiol. 2000;66(10):4266-71.

27. Doumith M, Buchrieser C, Glaser P, Jacquet C, Martin P. Differentiation of the major Listeria monocytogenes serovars by multiplex PCR. J Clin Microbiol. 2004;42(8):3819-22.

28. Guerra MM, Bernardo F, McLauchlin J. Amplified fragment length polymorphism (AFLP) analysis of Listeria monocytogenes. Syst Appl Microbiol. 2002;25(3):456-61.

29. Health Protection Agency. Questionnaires for the surveillance of Listeria monocytogenes infection in England \& Wales. Updated 20 February 2008. [Accessed 23 Jun 2008]. Available from: http://www.hpa.org.uk/webw/ HPAweb\&HPAwebStandard/HPAweb_C/1195733751673 $? p=1191942172760$

30. Office for National Statistics. Census 2001. England household form. [Accessed 5 May 2004]. Available from: http://www. statistics.gov.uk/census2001/pdfs/H1.pdf

31. Communities and Local Government. Indices of deprivation 2007. London: Communities and Local Government; 2009. [Accessed 5 Mar 2009]. Available from: http://www. communities.gov.uk/communities/neighbourhoodrenewal/ deprivation/deprivationo7/

32. StataCorp. Stata statistical software: release 10.1. College Station, TX: StataCorp LP; 2009.

33. Noble M, McLennan D, Wilkinson K, Whitworth A, Barnes $\mathrm{H}$, Dibben C. The English indices of deprivation 2007. London: Department for Communities and Local Government, HMSO 2008.

34. Dean AG., Dean JA, Burton, AH, Discker RC. Epi Info, Version 5: a word processing, database, and statistics programme for epidemiology on microcomputers. Georgia: USD Inc 1990.

35. Coleman MP, Babb P, Sloggett A, Quinn M, De Stavola B. Socioeconomic inequalities in cancer survival in England and Wales. Cancer. 2001;91:208-16.

36. Lahelma E, Martikainen P, Laaksonen M, Aittomaki A. Pathways between socioeconomic determinants of health. J Epidemiol Community Health. 2004;58(4):327-32.

37. McFadden E, Luben R, Bingham S, Wareham N, Kinmonth AL, Khaw KT. Social inequalities in self-rated health by age: crosssectional study of 22,457 middle-aged men and women. BMC Public Health. 2008;8:230.

38. Kumari M, Head J, Marmot M. Prospective study of social and other risk factors for incidence of type 2 diabetes in the Whitehall II study. Arch Intern Med. 2004;164(17):1873-80.
39. Tam CC, Rodrigues LC, O’Brien SJ. The study of infectious intestinal disease in England: what risk factors for presentation to general practice tell us about potential for selection bias in case-control studies of reported cases of diarrhoea. Int J Epidemiol. 2003;32(1):99-105.

40. Danesh J, Gault S, Semmence J, Appleby P, Peto R, Ben Shlomo Y, et al. Postcodes as useful markers of social class: population based study in 26,000 British households. BMJ. 1999;318(7187):843-4.

41. McLoone P, Ellaway A. Postcodes don't indicate individuals' social class. BMJ. 1999;319(7215):1003-4.

42. Swaminathan B, Gerner-Smidt P. The epidemiology of human listeriosis. Microbes Infect. 2007;9(10):1236-43.

43. Tinsley J, Jacobs M. Deprivation and ethnicity in England: a regional perspective. Regional Trends. 2006;39:19-28. [Accessed 2 Jun 2009]. Available from: http://www.statistics. gov.uk/articles/RegionalTrends/Article3RT39.pdf

44. Food Standards Agency (FSA). Pregnancy. London: FSA. [Accessed 17 Mar 2009]. Available from: http://www.eatwell. gov.uk/agesandstages/pregnancy/?lang=en

45. Cross M, Michaels M. Reaching the 'digitally disenfranchised'. In: the mix. London: Central Office of Information; 2009. p. 6-8. [Accessed 18 Aug 2009]. Available from: http://www.coi. gov.uk/documents/themix-summero9.pdf

46. Farber JM, Peterkin PI. Listeria monocytogenes, a food-borne pathogen. Microbiol Rev. 1991;55(3):476-511.

47. Local Authorities Coordinators of Regulatory Services. Summary of National Microbiological Studies carried out by LACORS and the Health Protection Agency (and formerly LACOTS/PHLS) in Partnership with LAs/Food Liaison Groups. Updated 25 February 2009. [Accessed 10 Jun 2009]. Available from: http://lacors.gov.uk/LACORS/ContentDetails. aspx?id $=3512$.

48. Little CL, Lock D, Barnes J, Mitchell RT. Microbiological quality of food in relation to hazard analysis systems and food hygiene training in UK catering and retail premises. Commun Dis Public Health. 2003;6(3):250-8.

49. Food Standards Agency (FSA). Safer food, better business. London: FSA. [Accessed 19 Aug 2009]. Available from: http://www.food.gov.uk/foodindustry/regulation/hygleg/ hyglegresources/sfbb/

50. Little CL, Barrett NJ, Grant K, McLauchlin J. Microbiological safety of sandwiches from hospitals and other health care establishments in the United Kingdom with a focus on Listeria monocytogenes and other Listeria species. J Food Prot. 2008;71(2):309-18.

51. Office for National Statistics. Pension trends. Updated 15 December 2008. [Accessed 19 Aug 2009]. Available from: http://www.statistics.gov.uk/downloads/theme_compendia/ pensiontrends/Pension_Trends_cho3.pdf

52. Office for National Statistics. Product price index 7112159900 : Food products excl beverages. Updated 5 August 2009. [Accessed 20 Aug 2009]. Available from: http://www.statistics. gov.uk/statbase/TSDdownload1.asp 